\title{
A family of diacyltrehaloses isolated from Mycobacterium fortuitum
}

\author{
Maria A. Ariza, Francisco Martín-Luengo and Pedro L. Valero-Guillén
}

Author for correspondence: Pedro L. Valero-Guillén. Tel: +34 68 307100. Fax: + 3468364150.

Departamento de Genética y Microbiología, Facultad de Medicina, Universidad de Murcia, 30100 Murcia, Spain

\begin{abstract}
A trehalose-containing glycolipid was detected in several strains of Mycobacterium fortuitum and characterized as 2,3-di-0-acyltrehalose (DAT) by combined NMR spectroscopy, IR spectroscopy, GLC and GLC-MS. Lipid constituents of the molecule were identified as a mixture of straight-chain (14-18 carbon atoms) and methyl-branched-chain (17-21 carbon atoms) fatty acyl groups. DAT was further fractionated by reverse phase TLC into four fractions that were designated DAT-I-DAT-IV. DAT-I contained 70-75\% straightchain acyl substituents (hexadecanoyl and octadecanoyl predominating) and 25-30\% 2-methyl branched substituents (mainly 2-methyl octadecadienoyl). DAT-II was composed of a mixture in which the acyl groups were almost exclusively 2-methyl branched, with 2-methyl octadecadienoyl and 2-methyl octadecen-2-oyl predominating. DAT-III, which was the major isolated fraction, consisted of compounds in which the ratio linear to branched acyl groups varied between 0.8 to $0.9,2$-methyl octadecen-2-oyl, hexadecanoyl and octadecanoyl being the most abundant. Finally, DAT-IV comprised a mixture of DAT molecules containing mostly 2-methyl octadecadienoyl, 2-methyl octadecen-2-oyl, 2-methyl eicosadienoyl and 2-methyl eicosen-2-oyl groups.
\end{abstract}

Keywords: Mycobacterium fortuitum, glycolipid, acyltrehalose

\section{INTRODUCTION}

Members of the genus Mycobacterium contain a great variety of glycolipids that can be classified into several structural types (Brennan, 1989). These molecules may play an important structural role, because most of them are located in the cell wall envelope (McNeil \& Brennan, 1991; Minnikin, 1982, 1991). They also show potential taxonomic value and, in some cases, constitute the basis for the definition of serovars within a given species (Denner et al., 1992). Some of these glycolipids are able to provoke non-specific membrane alterations (Fournié et al., 1989; Sut et al., 1990) and several physiopathological responses (Brownback \& Barrow, 1988; Pabst et al., 1988; Silva \& Faccioli, 1988) and have been implicated in the pathogenesis of the infections produced by mycobacteria (Draper, 1989; Rastogi \& David, 1988).

Apart from cord-factor (Asselineau \& Asselineau, 1978), sulpholipids (Goren et al., 1976) and other related trehalose-containing glycolipids (Asselineau \&

Abbreviations: DAT, 2,3-di-O-acyltrehalose; ${ }^{1} \mathrm{H}-{ }^{1} \mathrm{H}$ COSY, homonuclear ${ }^{1} \mathrm{H}-{ }^{1} \mathrm{H}$ chemical shift correlated spectroscopy; RPTLC, reverse phase thinlayer chromatography.
Asselineau, 1978), acylated trehaloses have been described in detail only in the species $M$. tuberculosis (Daffé et al., 1988; Minnikin et al., 1985) and M. fortuitum (Gautier et al., 1992; Hamid et al., 1993a; Sempere et al., 1993). Some structural similarities have been observed among the acyltrehaloses of the forementioned species; thus, both of them contain diacyl (Baer, 1993; Besra et al., 1992a; Gautier et al., 1992; Hamid et al., 1993a; Lemassu et al., 1991) and polyacyl (Daffé et al., 1988; Gautier et al., 1992; Minnikin et al., 1985; Sempere et al., 1993) derivatives of the disaccharide.

The diacyltrehalose (DAT) of $M$. fortuitum was only studied by Gautier et al. (1992) in the type strain of the species and characterized as a 2,3-di-O-acyltrehalose, with both straight-chain and 2-methyl branched fatty acyl substituents. In other studies, 2,3-di-O-acyltrehaloses were identified in 10 strains of $M$. fortuitum and their possible presence indicated in strains currently assigned to M. senegalense (Hamid et al., 1993b). This structure appears to be related to that present in M. tuberculosis (Baer, 1993; Besra et al., 1992a; Lemassu et al., 1991). In a recent study of a collection of strains of $M$. fortuitum (Sempere et al., 1993), we found two trehalose-containing glycolipids, one of which was not accurately identified (glycolipid B, 


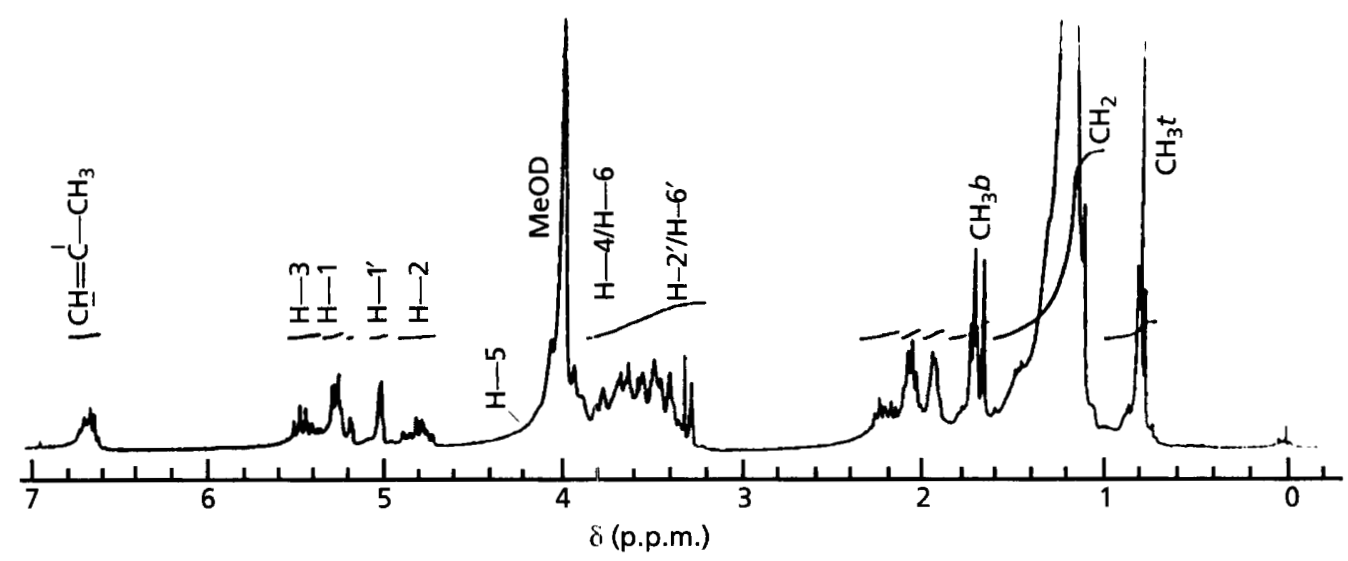

Fig. 1. ${ }^{1} \mathrm{H}$ NMR spectrum of DAT from $M$. fortuitum $M-431\left[300 \mathrm{MHz}, \mathrm{CDCl}_{3} / \mathrm{MeOD}(2: 1, \mathrm{v} / \mathrm{v})\right]$. The labelled resonances correspond to several protons of the trehalose (see Table 1) and the lipid portion of the molecule. $t$, terminal; $b$, branched; MeOD, deuteromethanol.

see Sempere et al., 1993). We have readdressed our attention to this substance and now confirm its structure as 2,3-di-O-acyltrehalose, similar to that of $M$. fortuitum type strain (Gautier et al., 1992; Hamid et al., 1993a). Our study extends this previous finding and, moreover, defines DAT as a mixture of four major compounds varying in the type and combinations of fatty acyl substituents. A more precise structural elucidation of this molecule is interesting because of its relationship to the antigenic DAT of M. tuberculosis (Minnikin et al., 1987; Papa et al., 1989; Ridell et al., 1992), formerly named glycolipid SI,IV (Daffé $e t$ al., 1989), for which some preliminary clinical studies have been reported (Martín-Casabona et al., 1992; Ridell et al., 1992).

\section{METHODS}

Strains and culture conditions. Strains M-50 (ATCC $6841^{\mathrm{T}}$ ), M-59, M-61, M-63, M-64, M-70, M-80, M-313, M-326, M-327, M-430 and M-431 (NCTC 8697) included in a previous work (Sempere et al., 1993) were reanalysed in the present study', together with two new clinical isolates: M-855 and M-858. For recovery of lipids, the strains were grown in Sauton broth at $35{ }^{\circ} \mathrm{C}$ for $10 \mathrm{~d}$.

Extraction and analysis of lipids. Cells were recovered $b y$ filtration and extracted overnight at $4{ }^{\circ} \mathrm{C}$, first with chloroform/ methanol $(1: 1, \mathrm{v} / \mathrm{v})$, then with chloroform/methanol $(2: 1$, $\mathrm{v} / \mathrm{v})$. The lipid extracts were combined, evaporated to dryness under $\mathrm{N}_{2}\left(40^{\circ} \mathrm{C}\right)$ and partitioned in chloroform $/$ methanol' water $(8: 4: 3$, by vol.). Lipids were recovered from the lower: (chloroform) phase, dried, redissolved in chloroform and analysed by TLC on aluminium-backed silica gel 60 plates. (Merck), employing chloroform/methanol/water $(60: 12: 1$, by vol.) as solvent. Plates were sprayed with molybdophosphoric acid $(5 \%, w / v$, in ethanol) to detect lipids and with orcinol $\left(0 \cdot 2 \%, \mathrm{w} / \mathrm{v}\right.$, in $\left.40 \% \mathrm{H}_{2} \mathrm{SO}_{4}\right)$ for sugars.

Structural analysis of DAT. The diacyltrehalose, or glycolipid B (see Sempere et al., 1993), was purified by column and TLC silica gel chromatography. The column was successively eluted with methanol $(0,2,5,7,10,15,20$ and $40 \%)$ in chloroform, DAT being recovered in the $10-15 \%$ methanol fractions. Final purification was achieved by preparative TLC on plastic-backed silica gel $60 \mathrm{~F}_{254}$ plates (Merck), with chloroform/methanol/ water $(60: 12: 1$, by vol.) as solvent. DAT was detected under UV light $(254 \mathrm{~nm})$ and eluted from the gel with chloroform/ methanol $(9: 1, \mathrm{v} / \mathrm{v})$.

IR spectroscopy was performed in a Nicolet $\mathrm{MX}-1$ apparatus using a $\mathrm{NaCl}$ cell. NMR $\left({ }^{1} \mathrm{H},{ }^{1} \mathrm{H}-{ }^{1} \mathrm{H} \mathrm{COSY}\right.$, and $\left.{ }^{13} \mathrm{C}\right)$ spectra were obtained in a Varian Unity 300 spectrometer with the sample $\left(15 \mathrm{mg} \mathrm{ml}^{-1}\right)$ dissolved in deuterochloroform/ deuteromethanol $(2: 1, \mathrm{v} / \mathrm{v})$. The presence of trehalose was confirmed by GLC as previously established (Sempere $e t$ al., 1993) and the structure of fatty acyl substituents determined by GLC and GLC-MS as reported previously (Valero-Guillén et al., 1987).

Fractionation of DAT. Purified DATs from strains M-431, M855 and M-858 were fractionated by reverse-phase TLC (RPTLC)employingRP-18 ${ }_{254}$ Splates(Merck), andchloroform/ methanol/water $(6: 15: 0 \cdot 1$, by vol.) as developing solvent (Besra et al., 1992a). Separated components were visualized under UV light $(254 \mathrm{~nm})$ and eluted from the gel with chloroform/ methanol $(9: 1, \mathrm{v} / \mathrm{v})$. Trehalose and fatty acyl groups of the different DATs were determined as above. Fatty acid methyl esters were purified by preparative silica gel TLC, with dichloromethane as solvent, before GLC analysis, since a component of the RP-18 plates presented a similar retention time to that of 2-methyl heptadecen-2-oic methyl ester.

\section{RESULTS}

\section{Structure of DAT}

The whole glycolipid patterns of most strains studied have already been reported (Sempere et al., 1993), and the current results confirm previous findings. Strains M-855 and M-858 contained two glycolipids, the more apolar corresponded to a 2,3,4-tri-O-acyltrehalose and the more polar to the designated glycolipid B (Sempere et al., 1993), whose detailed structure is the subject of the present study.

As previously described (Sempere et al., 1993), the glycolipid fraction under investigation contained tre- 
Table 1. ${ }^{1} \mathrm{H}-{ }^{1} \mathrm{H}$ COSY analysis of DAT of $M$. fortuitum $\mathrm{M}$ 431: chemical shifts of the protons assigned to trehalose

\begin{tabular}{|cc|}
\hline Proton & $\begin{array}{c}\text { Chemical shift } \\
\text { (p.p.m.) }\end{array}$ \\
\hline H-1 & $5 \cdot 29$ \\
H-2 & $4 \cdot 80$ \\
H-3 & $5 \cdot 45$ \\
H-4 & $3 \cdot 44$ \\
H-5 & $4 \cdot 08$ \\
H-6 & $3 \cdot 38$ \\
H-1' & $5 \cdot 03$ \\
H-2' & $3 \cdot 76$ \\
H-3', H-4', H-5', H-6 & ND \\
\hline
\end{tabular}

ND, not detected (included in the region $3 \cdot 4-4 \cdot 0$ p.p.m. in each case).

halose as the only sugar compound. The fatty acyl constituents were now precisely characterized as tetradecanoyl $(14: 0)(2-4 \%)$, hexadecenoyl $(16: 1)(3-6 \%)$, hexadecanoyl (16:0) (15-25\%), 2-methyl hexadecen-2oyl (2-Me 16:1) (3-6\%), octadecenoyl (18:1) (3-7\%), octadecanoyl (18:0) (8-20\%), 2-methyl heptadecen-2-oyl (2-Me 17:1) (3-7\%), 2-methyl octadecadienoyl (one double bond at position 2) (2-Me 18:2) (9-15\%), 2methyl octadecen-2-oyl (2-Me 18:1) (20-35\%), 2-methyl eicosadienoyl (one double bond at position 2) (2-Me 20:2) $(3-8 \%)$ and 2-methyl eicosen-2-oyl (2-Me 20:1) (2-5\%). GLC profiles and mass spectra of these compounds were identical to those liberated from the triacyltrehalose of the same strains (Sempere et al., 1993). IR spectra corroborated the presence of trehalose (absorption band at $\left.808 \mathrm{~cm}^{-1}\right)$, and methyl branch $\left(1360 \mathrm{~cm}^{-1}\right)$, and unsaturation at position $2\left(1460 \mathrm{~cm}^{-1}\right)$ in the lipid portion of the molecule.

The ${ }^{1} \mathrm{H}$ NMR spectrum (Fig. 1) revealed signals between 0.8 p.p.m. and 6.7 p.p.m., with characteristic signals centred at 0.8 p.p.m. (terminal $-\mathrm{CH}_{3}$ ), 1.2 p.p.m. (- $\mathrm{CH}_{2}-$ ), 1.71 p.p.m. (methyl branch), 1.93 p.p.m. (- $\mathrm{CH}_{2}-\mathrm{CH}=\mathrm{CH}-$ ), 2.04 p.p.m. $\quad\left(-\mathrm{CH}_{2}-\mathrm{CH}=\right.$ $\mathrm{C}-\mathrm{CH}_{3}$ ), 5.26 p.p.m. (- $\mathrm{C} \underline{\mathrm{H}}=\mathrm{C} \underline{\mathrm{H}}-$ ) and 6.65 p.p.m. $\left(-\mathrm{CH}_{2}-\mathrm{CH}=\mathrm{C}-\mathrm{CH}_{3}\right)$. Anomeric protons of the trehalose resonated at 5.29 p.p.m. (H-1) and 5.03 p.p.m. $\left(\mathrm{H}-1^{\prime}\right)$. Other ring protons of the disaccharide were assigned with the aid of ${ }^{1} \mathrm{H}^{1}{ }^{1} \mathrm{H}$ COSY NMR (Table 1): connectivities from $\mathrm{H}-1$ through $\mathrm{H}-6$ resonances, and from $\mathrm{H}-1^{\prime}$ to $\mathrm{H}-2^{\prime}$ resonances were observed. In contrast, $J_{1,2}$ was $<4 \mathrm{~Hz}$, and $J_{2,3}$ and $J_{3,4}$ were $9.9 \mathrm{~Hz}$. These data clearly proved an $\alpha, \alpha^{\prime}$ configuration for trehalose, and the presence of two acyl groups at position 2 and 3 (chemical shift of H-2 $=4.80$ p.p.m.; chemical shift of $\mathrm{H}-3=$ 5.45 p.p.m.) of the same glucosyl residue of the trehalose. These data enabled us to identify the glycolipid as 2,3-di$\mathrm{O}$-acyltrehalose.

In the ${ }^{13} \mathrm{C}$ NMR spectrum (Fig. 2) we found two signals for the anomeric carbons at 91.89 p.p.m. (C-1) and $94 \cdot 80$ p.p.m. (C-1'). The resonances of $\mathrm{C}-2$ to $\mathrm{C}-5$ and $\mathrm{C} 2^{\prime}$ to $\mathrm{C}^{\prime}$ ' were located between $69 \cdot 0$ p.p.m. and 75.0 p.p.m. Two resonances situated at 60.99 p.p.m. and 61.63 p.p.m. were attributed to the C- 6 carbons of the sugar. The remaining signals of this spectrum confirmed the structural details of the fatty acyl carbons of the molecule, thus supporting the identification proposed above.

\section{Fractionation of DAT}

DATs from strains M-431, M-855 and M-858 were subjectd to fractionation by RPTLC employing the solvent system described by Besra et al. (1992a). Four spots were detected and designated DAT-I $\left(R_{F}=0.49\right)$, DAT-II $\left(R_{F}=0 \cdot 46\right)$, DAT-III $\left(R_{F}=0.43\right)$ and DAT-IV $\left(R_{F}=0.39\right)$ (Fig. 3). Densitometric determinations of the intensities of the spots, indicated that the major component was DAT-III ( $60 \%)$, followed by DAT-II $(25 \%)$, DAT-IV (10\%) and DAT-I (5\%).

The different DATs were degraded by saponification and the liberated acids identified and quantified by GLC as

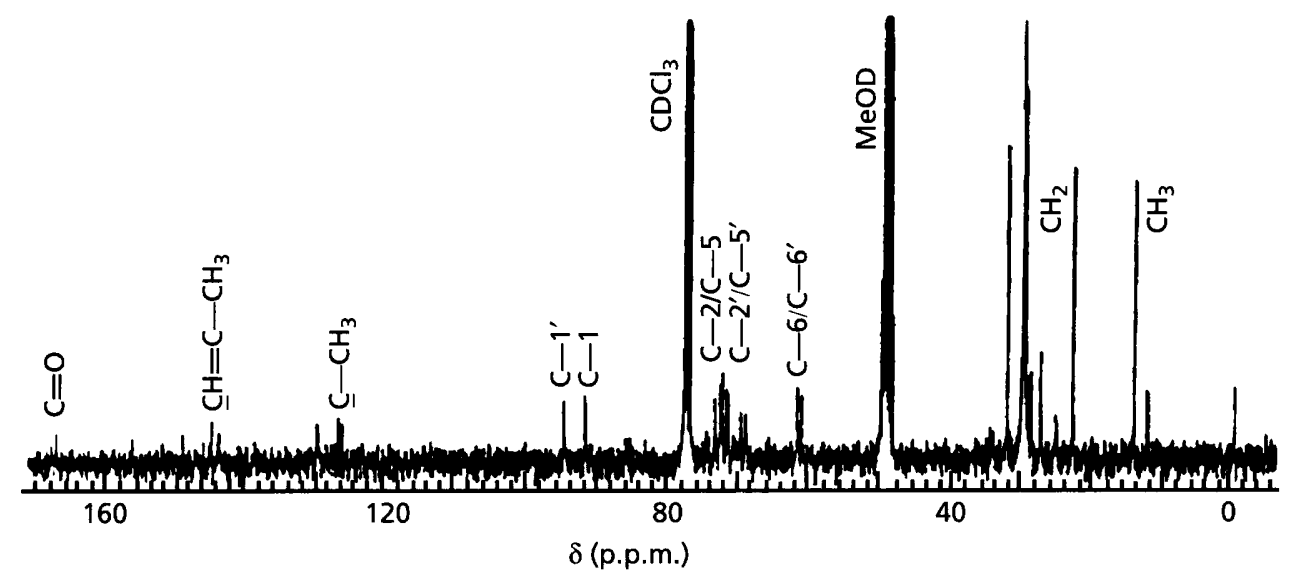

Fig. 2. ${ }^{13} \mathrm{C}$ NMR spectrum of DAT from $M$. fortuitum M-431. Principal signals assigned to the lipid moiety resonances and trehalose carbon resonances are illustrated. MeOD, deuteromethanol. 


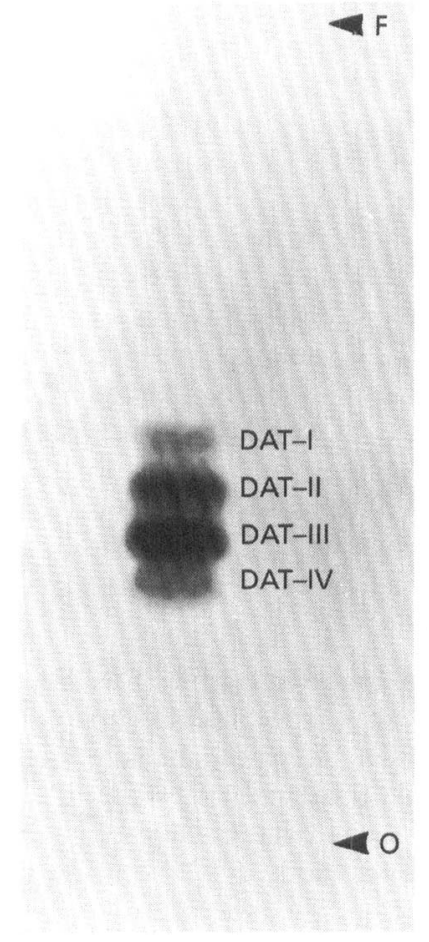

Fig. 3. RPTLC $(10 \times 10 \mathrm{~cm})$ of DAT from $M$. fortuitum $M-431$. The solvent was chloroform/methanol/water $(6: 15: 0 \cdot 1$, by vol.). Plates were sprayed with molybdophosphoric acid $(5 \%, w / v$, in ethanol). The positions of DAT-I-IV are indicated. 0 , origin; $F$, solvent front.

methyl esters. Table 2 shows the molar percentages of these compounds found in the four DATs of the three strains of $M$. fortuitum examined.
In DAT-I the straight-chain fatty acyl groups (70-75\%) predominated over the methyl-branched ones (25-30\%). In this case, and given the composition of the remaining DATs (see below), we assumed that this family was composed of two mixtures of DATs: DAT-Ia, with only straight-chain acyl substituents (a main component could be formulated as hexadecanoyl, octadecanoyl trehalose) and DAT-Ib, with two branched-chain substituents (with a probable main component formulated as di-2-methyl octadecadienoyl trehalose).

DAT-II of the strain M-855 (Table 2) was composed of mixtures of DATs in which the lipid constituents were exclusively methyl-branched fatty acyl groups. The more abundant molecular species could come from the combination of 2-Me 18:2 and 2-Me 18:1 with trehalose. The presence of linear acyl groups in DAT-II of M-431 and M855 strains (Table 2) would derive from partial mixtures of DAT-II and DAT-III and/or DAT-I, taking into account their close TLC mobilities.

In DAT-III the fatty acyl groups ranged from 14 to 21 carbon atoms, the predominant being 16:0,18:0 and 2Me 18:1. The ratio straight-chain to branched-chain fatty acyl groups varied between $0 \cdot 8$ and $0 \cdot 9$.

Finally, in DAT-IV only methyl branched acyl groups were found and identified as $2-\mathrm{Me} 18: 2,2-\mathrm{Me} 18: 1,2-\mathrm{Me}$ $20: 2$ and $2-\mathrm{Me} 20: 1$. From the data of Table 2, a principal component comprising the combination of $2-\mathrm{Me} 18: 1$ and 2-Me 20:1 with trehalose was assumed for this DAT.

\section{DISCUSSION}

From the general data presented in this work, it is now clear that the lipid formerly named 'glycolipid B' (Sempere et al., 1993) is a 2,3-di-O-acyltrehalose, similar to

\section{Table 2. Fatty acid composition of different DATs of $M$. fortuitum}

Fatty acids were identified by the number of carbon atoms and double bonds. Me, methyl; -, not detected. The results are the mean values of two different analyses of the same lipid fraction (the so value for the major fatty acid(s) in each DAT was $<5 \%$ ).

\begin{tabular}{|c|c|c|c|c|c|c|c|c|c|c|c|c|}
\hline \multirow[t]{2}{*}{ Strain } & \multirow[t]{2}{*}{ DAT } & \multicolumn{11}{|c|}{ Fatty acids (molar \%) } \\
\hline & & $14: 0$ & $16: 1$ & $16: 0$ & $\begin{array}{c}2-\mathrm{Me} \\
16: 1\end{array}$ & $18: 1$ & $18: 0$ & $\begin{array}{c}2-\mathrm{Me} \\
17: 1\end{array}$ & $\begin{array}{c}2-\mathrm{Me} \\
18: 2\end{array}$ & $\begin{array}{c}2-\mathrm{Me} \\
18: 1\end{array}$ & $\begin{array}{c}2-\mathrm{Me} \\
20: 2\end{array}$ & $\begin{array}{c}2-\mathrm{Me} \\
20: 1\end{array}$ \\
\hline \multirow[t]{4}{*}{ M-431 } & I & 8 & 4 & 29 & 12 & 11 & 15 & 5 & 16 & - & - & - \\
\hline & II & - & - & 7 & 10 & 2 & 8 & 13 & 17 & 31 & 11 & 1 \\
\hline & III & 2 & 2 & 16 & 2 & 3 & 25 & 2 & 5 & 35 & 5 & 3 \\
\hline & IV & - & - & - & - & - & - & - & 12 & 48 & 10 & 30 \\
\hline \multirow[t]{4}{*}{ M-855 } & I & 5 & 4 & 24 & 5 & 10 & 26 & - & 21 & - & - & - \\
\hline & II & - & - & - & 7 & - & - & 11 & 34 & 40 & 6 & 2 \\
\hline & III & 6 & 1 & 18 & - & 4 & 16 & 5 & 10 & 30 & 5 & 3 \\
\hline & IV & - & - & - & - & - & - & - & 18 & 41 & 10 & 31 \\
\hline \multirow[t]{4}{*}{ M-858 } & I & 5 & 9 & 21 & 5 & 16 & 18 & 4 & 20 & - & - & - \\
\hline & II & - & - & 11 & 8 & 6 & 9 & 8 & 30 & 19 & 7 & 1 \\
\hline & III & 2 & 2 & 10 & 2 & 5 & 26 & 6 & 5 & 35 & 5 & 2 \\
\hline & IV & - & - & - & - & - & - & - & 11 & 46 & 11 & 32 \\
\hline
\end{tabular}


the lipid described for the type strain of $M$. fortuitum (Gautier et al., 1992). Our results also confirm that this glycolipid is widely distributed in the species, thus representing a useful chemical taxonomic tool, like its homologous 2,3,4-tri- $O$-acyltrehalose, in the differentiation of members of the $M$. fortuitum complex ( $M$. fortuitum, $M$. peregrinum, $M$. abscessus, $M$. chelonae) that contain specific glycolipid profiles (Hamid et al., 1993b; LópezMarín et al., 1991; Tsang et al., 1984). DAT is an amphipathic molecule because the two acyl substituents occupy the same glucosyl residue. In accordance with the molecular models of the cell envelope of mycobacteria (McNeil \& Brennan, 1981; Minnikin, 1982, 1991) DAT could be located in the cell wall, interacting with the hydrophobic part of the mycoloyl-arabinogalactan, or even in the plasma membrane.

The overall structure of $M$. fortuitum DAT is strikingly similar to that of M. tuberculosis (Baer, 1993; Besra et al., 1992a; Lemassu et al., 1991). However, it is also evident that branched fatty acyl groups are structurally more complex in the latter species, where the presence of mixtures of straight-chain fatty acyl substituents and mycosanoyl, mycolipanoyl and phthienoyl groups has been documented (Baer, 1993; Besra et al., 1992a; Lemassu et al., 1991; Minnikin et al., 1985). Resolution of DAT from $M$. tuberculosis by TLC yielded four families of glycolipids: the major ones were resolved by RPTLC (Besra $t$ al., 1992a). A glycolipid (DAT 1a) obtained in such a way, was characterized as a DAT in which octadecanoyl was located at position 2 and mycosanoyl (2,4-dimethyl docosanoyl) was at position 3 of the same glucosyl residue (Besra et al., 1992a). From the fast-atom bombardment mass spectra (Baer, 1993; Lemassu et al., 1991) and lipid analysis of other resolved DATs (Besra et al., 1992a), it seems that the overall fatty acyl distribution in DATs of M. tuberculosis is similar to that of DAT 1a, that is one straight-chain acyl group and one branchedchain acyl group per molecule.

Taking into account the data of Table 2 it can be suggested that in $M$. fortuitum, unlike $M$. tuberculosis, three different combinations of fatty acyl substituents are present in its DATs: (1) straight-chain plus straight-chain (DAT-Ia), (2) branched-chain plus branched-chain (DAT-Ib, DATII and DAT-IV), and (3) straight-chain plus branchedchain (DAT-III) (note that the linear to branched acyl group ratio is approximately one). DAT-III is the principal and could be considered the more closely related to DATs of M. tuberculosis. At present, however, it is not known if DAT-III follows the same pattern of substitution as that found in DAT 1a.

DATs from $M$. tuberculosis have been envisaged as simplified versions of lipo-oligosaccharides (LOS) in which an acylated trehalose is also an integral part of the molecule (Brennan, 1989). Both LOS and DATs are present in several strains of $M$. tuberculosis (Lemassu et al., 1992), but similar evidence is not thus far available for $M$. fortuitum. However, in a recent investigation (Besra $e t$ al., 1992b), a tetra-O-acyl triglucosyl glycolipid has been described in the latter species. The structure of the acyl substituents suggests a relation between this compound and the DATs and triacyltrehaloses previously characterized in M. fortuitum (Gautier et al., 1992; Hamid et al., 1993a; Sempere et al., 1993), although clearly more extended analyses are required to clarify if LOS and DATs coexist in this species.

Another point arising from this work is the possible antigenicity of the DATs of $M$. fortuitum. As mentioned, these compounds present an overall structure related to the strong antigenic DAT of M. tuberculosis (Papa et al., 1989; Ridell et al., 1992). Acyltrehaloses from M. fortuitum have been shown to be antigenic (Hamid et al., 1993a) and the relative structural simplicity of DAT raises the possibility of its chemical synthesis for use in serodiagnosis (Baer \& Wu, 1993; Wallace \& Minnikin, 1993).

\section{ACKNOWLEDGEMENTS}

This work was supported by contract FISS 93/0463, Ministerio de Sanidad y Consumo, Spain. Thanks are due to Dr M. Gacto (Departamento Genética y Microbiología, Universidad de Murcia, Spain) for the revision of the manuscript.

\section{REFERENCES}

Asselineau, C. \& Asselineau, J. (1978). Trehalose-containing glycolipids. Prog Chem Fats Otber Lipids 16, 56-99.

Baer, H. H. (1993). The structure of an antigenic glycolipid (SL-IV) from Mycobacterium tuberculosis. Carbobydr Res 240, 1-22.

Baer, H. H. \& Wu, X. (1993). Synthesis of $\alpha, \alpha$-trehalose 2,3- and 2,3'diesters with palmitic and stearic acid: potential immunoreactants for the serodiagnosis of tuberculosis. Carbobydr Res 238, 215-230.

Besra, G. S., Bolton, R. C., McNeil, M. R., Ridell, M., Simpson, K. E., Glushka, J., van Halbeek, H., Brennan, P. J. \& Minnikin, D. E. (1992a). Structural elucidation of a novel family of acyltrehaloses from Mycobacterium tuberculosis. Biochemistry 31, 9832-9837.

Besra, G. S., McNeil, M. R. \& Brennan, P. J. (1992b). Characterization of the specific antigenicity of Mycobacterium fortuitum. Biochemistry 31, 6504-6509.

Brennan, P. J. (1989). Structure of mycobacteria: recent development in defining cell wall carbohydrates and proteins. J Infect Dis 11, S420-S430.

Brownback, P. E. \& Barrow, W. W. (1988). Modified lymphocyte response to mitogens after intraperitoneal injection of glycopeptidolipid antigens from Mycobacterium avium complex. Infect Immun 56, 1044-1050.

Daffé, M., Lacave, C., Lanéelle, M. A., Gillois, M. \& Lanéelle, G. (1988). Polyphthienoyl trehalose, glycolipids specific for virulent strains of tubercle bacillus. Eur J Biochem 172, 579-584.

Daffé, M., Papa, F., Laszlo, A. \& David, H. L. (1989). Glycolipids of recent clinical isolates of Mycobacterium tuberculosis: chemical characterization and immunoreactivity. J Gen Microbiol 135, 2759-2766.

Denner, J. C., Tsang, A. Y., Chatterjee, D. \& Brennan, P. J. (1992). Comprehensive approach to identification of serovars of $\mathrm{Myco-}$ bacterium avium complex. J Clin Microbiol 30, 473-478.

Draper, P. (1989). Pathogenic mechanisms and immunobiology of mycobacteria. Curr Opin Infect Dis 2, 796-803.

Fournié, J. J., Adams, E., Mullins, R. J. \& Basten, A. (1989). Inhibition of human lymphoproliferative response by mycobacterial phenolic glycolipids. Infect Immun 57, 3653-3659.

Gautier, N., López-Marín, L. M., Lanéelle, M. A. \& Daffé, M. (1992). Structure of mycoside $F$, a family of trehalose-containing 
glycolipids of Mycobacterium fortuitum. FEMS Microbiol Lett 98, 81-88.

Goren, M. B., Brokl, D., Roller, P., Fales, H. M. \& Das, B. C. (1976). Sulphatides of Mycobacterium tuberculosis: the structure of the principal sulphatide (SL-I). Biochemistry 15, 2728-2735.

Hamid, M. E., Fraser, J. L., Wallace, P. A., Besra, G., Goodfellow, M., Minnikin, D. E. \& Ridell, M. (1993a). Antigenic glycolipids of Mycobacterium fortuitum based on trehalose acylated with 2-methyloctadec-2-enoic acid. Lett Appl Microbiol 16, 132-135.

Hamid, M. E., Minnikin, D. E., Goodfellow, M. \& Ridell, M. (1993b). Thin-layer chromatography analysis of glycolipids and mycolic acids from Mycobacterium farcinogenes, Mycobacterium senegalense and related taxa. Zentralbl Bakteriol 279, 354-367.

Lemassu, A., Lanéelle, M. A. \& Daffé, M. (1991). Revised structure of trehalose-containing immunoreactive glycolipid of Mycobacterium tuberculosis. FEMS Microbiol Lett 78, 171-176.

Lemassu, A., Vincent Lévy-Frebault, V., Lanéelle, M. A. \& Daffé, M. (1992). Lack of correlation between colony morphology and lipooligosaccharide content in the Mycobacterium tuberculosis complex. J Gen Microbiol 138, 1535-1541.

López-Marín, L. M., Lanéelle, M. A., Promé, D., Daffé, M., Lanéelle, G. \& Promé, J. C. (1991). Glycopeptidolipids from Mycobacterium fortuitum: a variant in the structure of C-mycoside. Biochemistry 30, 10536-10542.

McNeil, M. \& Brennan, P. J. (1991). Structure, function and biogenesis of cell envelope of mycobacteria in relation to bacterial physiology, pathogenesis and drug resistance; some thoughts and possibilities arising from recent structural information. Res Microbiol 142, 451-463.

Martín-Casabona, N., González-Fuente, T., Papa, F., RosellóUrgel, J., Vidal-Pla, R., Codina-Grau, G. \& Ruiz-Camps, I. (1992). Time course of anti-SL-IV immunoglobulin $G$ antibodies in patients with tuberculosis and tuberculosis-associated AIDS. J Clin Microbiol 30, 354-358.

Minnikin, D. E. (1982). Lipids: complex lipids, their chemistry, biosynthesis and roles. In The Biology of the Mycobacteria, vol. 1, pp. 95-184. Edited by C. Ratledge \& J. Stanford. London: Academic Press.

Minnikin, D. E. (1991). Chemical principles in the organization of lipid components in the mycobacterial cell envelope. Res Microbiol $142,423-427$.

Minnikin, D. E., Dobson, G., Sesardic, D. \& Ridell, M. (1985).
Mycolipenates and mycolipanolates of trehalose from Mycobacterium tuberculosis. J Gen Microbiol 131, 1369-1374.

Minnikin, D. E., Ridell, M., Parlett, J. H. \& Bolton, R. C. (1987). Direct detection of Mycobacterium tuberculosis lipid antigens by thinlayer chromatography. FEMS Microbiol Lett 48, 175-177.

Pabst, M. J., Gross, J. M., Brozna, J. P. \& Goren, M. B. (1988). Inhibition of macrophage priming by sulfatide from Mycobacterium tuberculosis. Infect Immun 140, 634-640.

Papa, F., Cruaud, P. \& David, H. L. (1989). Antigenicity and specificity of selected glycolipid fractions from Mycobacterium tuberculosis. Res Microbiol 140, 569-578.

Rastogi, N. \& David, H. L. (1988). Mechanisms of pathogenicity in mycobacteria. Biochimie 70, 1101-1120.

Ridell, M., Wallerström, G., Minnikin, D. E., Bolton, R. C. \& Magnusson, M. (1992). A comparative serological study of antigenic glycolipids from Mycobacterium tuberculosis. Tubercle Lung Dis 73, 101-105.

Sempere, M., Valero-Guillén, P. L., de Godos, A. \& MartínLuengo, F. (1993). A triacyltrehalose containing 2-methyl-branched unsaturated fatty acyl groups isolated from Mycobacterium fortuitum. $J$ Gen Microbiol 139, 585-590.

Silva, C. \& Faccioli, L. H. (1988). Tumor necrosis factor (cachectin) mediates induction of cachexia by cord factor from mycobacteria. Infect Immun 56, 3067-3071.

Sut, A., Sirugue, S., Sixou, F., Lakdar-Ghazal, F., Tocanne, J. F. \& Lanéelle, G. (1990). Mycobacterial glycolipids as potential pathogenicity effectors: alterations of model and natural membranes. Biochemistry 29, 8498-8502.

Tsang, A. Y., Barr, V. L., McClatchy, J. K., Goldberg, M., Drupa, J. \& Brennan, P. J. (1984). Antigenic relationships of the Mycobacterium fortuitum-Mycobacterium chelonae complex. Int $J$ Syst Bacteriol 34, 35-44.

Valero-Guillén, P. L., Martín-Luengo, F., Larsson, L. \& Jiménez, J. (1987). Demonstration of 2-methyl branched chain fatty acids in some rapid-growing mycobacteria. FEMS Microbiol Lett 44, 303-305.

Wallace, P. A. \& Minnikin, D. E. (1993). Synthesis of 2,3-di-Opalmitoyl- $\alpha, \alpha$-trehalose via a novel tri-protected trehalose intermediate. J Chem Soc Chem Commun, 1292-1293.

Received 20 December 1993; revised 21 February 1994; accepted 14 March 1994. 